\title{
¿MERCADOS, MUSEOS O MALLS? \\ LA GENTRIFICACIÓN DE LOS MERCADOS MUNICIPALES \\ EN BARCELONA Y MADRID
}

\author{
Markets, Museums or Malls? \\ Gentrification of Public Markets \\ IN BARCELONA AND MADRID
}

\section{Adrián Hernández Cordero ${ }^{1}$ Stoyanka Andreeva Eneva}

Resumen: Los mercados públicos o municipales se están convirtiendo en equipamientos estratégicos en el nuevo escenario urbano. La transformación del modelo de consumo y ciudad en relación con los mercados todavía no ha sido suficientemente estudiada. El objetivo del presente documento consiste en analizar las mutaciones que experimentan algunos mercados públicos a partir del estudio y comparación de las dos principales ciudades españolas: Barcelona y Madrid. Se busca mostrar que a pesar de las diferencias en los modelos de intervención y gestión se producen patrones similares: los mercados turistificados y los mercados-mall. Primero se revisan las discusiones teóricas en torno al concepto de gentrificación comercial. Después, se analizan las políticas públicas en Madrid y Barcelona respecto a los mercados municipales. Finalmente, se estudian cuatro mercados, dos en cada ciudad, para mostrar las transformaciones que experimentan.

\footnotetext{
${ }^{1}$ Doctor en geografía por la Universidad Autónoma de Barcelona. Mientras se realizó esta investigación gozó de una beca doctoral del Conacyt, México. Correo electrónico: adn212@gmail.com

${ }^{2}$ Máster en antropología de orientación pública, Universidad Autónoma de Madrid. Correo electrónico: tani_eneva@yahoo.com

Fecha de recepción: 2809 15; Fecha de aceptación: 230416.
}

(c) EY-NC-ND Páginas 143-174. 
Además, se incluye un epílogo para llamar la atención sobre un par de mercados que experimentan un proceso de metamorfosis que será importante seguir.

Palabras clave: gentrificación, turistificación, mercados públicos, Barcelona, Madrid.

Abstract: Public markets are becoming strategic spaces in the current urban scenario. The purpose of this paper is to analyze markets' transformations comparing the two main Spanish cities: Madrid and Barcelona. Despite the difference in city management and urban interventions, three common patterns could be identified: gentrified markets, markets converted in malls and markets in transition. Firstly, theoretical discussions about commercial gentrification concept will be reviewed. Then, local public policies regarding markets will be analyzed. Finally, four markets — two in each city - are studied to show the changes they experience. In addition, an epilogue is included to draw attention to a few markets experiencing a process of metamorphosis that will be important to follow.

Keywords: gentrification, touristification, public markets, Barcelona, Madrid.

\section{Gentrificación comercial y mercados municipales ${ }^{3}$}

El concepto gentrificación ${ }^{4}$ tiene más de cinco décadas de existencia y durante ese periodo se han agregado dimensiones de complejidad que han diversificado su estudio. Una de ellas es la gentrificación comercial,

\footnotetext{
${ }^{3}$ Una versión preliminar se presentó en el $1{ }^{\text {er }}$ Congreso Internacional de Antropología AIBR, celebrado de 7 a 10 de julio de 2015 en Madrid, España.

${ }^{4}$ Siguiendo a Slater (2011), se entiende gentrificación como el proceso de trasformación mediante el cual algunas zonas urbanas experimentan un proceso de revalorización económica a través de acuerdos institucionales entre ámbitos públicos y privados, teniendo como consecuencia el desplazamiento de población de ingresos bajos y la llegada de sectores de mayores recursos.
} 
que se caracteriza por desentrañar la forma en que la venta al por menor es desplazada por establecimientos de un estatus más alto que satisfacen la demanda de la clase media urbana. A este tipo de gentrificación se ha prestado poca atención y se ha estudiado como parte o consecuencia del proceso de revalorización urbana. En general, todavía no se consigue ver como un problema social, dado que la llegada de nuevos negocios e inversiones a barrios que han sufrido abandono y deterioro se entiende como revitalización o recuperación, ocultando el desplazamiento de personas y actividades comerciales (Zukin y otros, 2009).

La gentrificación comercial ha sido estudiada en dos ámbitos espaciales, en los barrios gentrificados y en los mercados municipales. Respecto al primer tema, se ha enfocado desde diferentes perspectivas y contextos, poniendo el énfasis en el desplazamiento de antiguos comerciantes y la creación de ciudades-marca como ocurrió en Manchester (Massey, 2005), así como el papel del gobierno local en el diseño de políticas de regeneración urbana destinadas a atraer a las denominadas clases creativas a ciertas zonas implicando la apertura de locales relacionados con la promoción de la cultura y de la gastronomía gourmet y desplazando a comercios de tipo étnico, como ocurrió en el barrio de Russafa - Valencia (Romero y Lara, 2015). Otros ejemplos relevantes encontramos en el análisis del papel de las nuevas identidades que se crean a través del consumo en Sydney (Bridge y Dowling, 2001), la búsqueda de una autenticidad socialmente construida y convertida en experiencia de consumo en Nueva York (Zukin y otros, 2009) o la creación y la defensa de una propiedad simbólica del paisaje comercial en Los Ángeles (Deener, 2007).

Mientras que el tema de los mercados fue analizado por González y Waley (2012), a partir del estudio de caso del Mercado de Kirkgate, en Leeds, demostrando la forma en que estos equipamientos se asumen como la nueva frontera de la gentrificación. Desde la visión gubernamental y empresarial los mercados son representados como sitios deteriorados, salvajes y sucios. La generación de este discurso clasista y racista sobre los centros de abasto popular justifica su rescate y el posterior redescubrimiento de su valor comercial y urbanístico. De esta forma, se "rejuvenecen" con la inclusión de locales de productos 
gourmet que suelen influir en la expulsión de las paradas de los comerciantes más precarios, quienes cuentan con menor capacidad económica para adaptarse a las nuevas demandas de consumo.

Las reformas realizadas a los mercados municipales por los gobiernos implican la incorporación de nuevas funciones bajo la premisa de "modernizarlos y actualizarlos” (Bravo y Porretta, 2009). La recomendación de incorporar supermercados o tiendas que no sean de alimentación es defendida por distintos organismos como el Instituto Municipal de Mercados de Barcelona —en el Plan estratégico 2015-2025- que exhorta este tipo de uso "mixto" como forma de rentabilizar y modernizar el espacio, o Mercasa, que a su vez apuesta por el objetivo de convertir los mercados en "centros especializados en productos de la compra cotidiana" y "gestionarlos profesionalmente como una gran superficie" (Alonso, 2008). Sin embargo, este tipo de discursos tecnocráticos se centran excesivamente en la remodelación física de los edificios y en aplicar modelos de gestión propios de grandes empresas con el objetivo de aumentar la rentabilidad, sin tener en cuenta factores sociales y culturales relacionados con el funcionamiento y el papel histórico de los mercados en sus zonas de influencia.

Las transformaciones mencionadas se intentan legitimar a través de un discurso que avala el cambio como modernización, es decir, adaptación a los nuevos tiempos, hábitos de consumo y formas de vida en el barrio; marginalizando a los anteriores como atrasados, no adecuados, y orientando las opciones de consumo hacia las nuevas prácticas. Es una conversión tanto de los mercados como de su entorno presentada como evolución. Sin embargo, no siempre es lineal ni homogénea. En distintas zonas de un barrio en proceso de gentrificación podemos encontrar agrupaciones de vecinos y de comercios según el nivel de renta y tipo de producto/precio. Este tipo de zonificación es evidencia, por un lado, de la segregación que crea la gentrificación y, por otro, de las contradicciones y luchas de permanencia y/o apropiación del barrio.

Siguiendo la línea del estudio de los mercados que nos ocupará en el presente documento, se puede sostener que no sólo se trata de una transformación física del espacio, sino también simbólica. El consumo representa una acción que organiza la vida cotidiana en el barrio y es 
un factor que crea identidad. Además de la etnicidad y nacionalidad, el nivel de ingresos o el grupo profesional, el tipo específico de consumo es el que conforma las nuevas identidades y grupos de un barrio (Zukin, 2008), lo cual convierte los mercados en lugares vulnerables a la gentrificación, ya que los nuevos habitantes demandan un espacio de consumo que satisfaga sus demandas materiales, así como las necesidades de capital social y cultural (Zukin, 1991; Patch, 2008). En este sentido, el desplazamiento no es sólo expresión de poder financiero, sino también cultural (Zukin, 2010). Al expulsar los comercios antiguos del barrio/mercado, los nuevos negocios reclaman una superioridad moral y estética como símbolo del crecimiento económico y de la calidad que los puestos de venta anteriores no eran capaces de ofrecer a los clientes.

La gentrificación puede implicar que los mercados pierdan su esencia como espacio público, como se ha visto en otros trabajos (HernándezCordero, 2014). Algunas de las características que convierten a los mercados tradicionales en espacios públicos y de socialización se han descrito en distintos estudios etnográficos como el de Robles (2010), quien analiza las interacciones cotidianas que tienen lugar en ellos. Watson (2009) también aborda la organización del espacio que facilita los encuentros informales: la proximidad entre los puestos que deriva en unas relaciones sociales inevitables entre los comerciantes, el espacio abierto sin restricciones de entrada o salida que representa el mercado, la existencia de cafeterías y bares que, como servicios que complementan la oferta comercial, también son espacios de socialización. Robles (2010) indica que en los mercados existe una personalidad propia del pequeńo comercio que favorece la interacción consumidor-comerciante más allá de una mera transacción económica.

Las relaciones sociales que se generan en los mercados pueden producir un intenso "sentido de lugar" (Massey, 1995) que ha llevado a generar procesos de resistencia o contragentrificación como ocurrió en Tucumán. Boldrini y Malizia (2014) comparan el proceso de gentrificación de dos mercados localizados en el centro de esa ciudad y muestran la forma en la cual uno de ellos toma un rumbo diferente a partir de un proceso de movilización social que aglutinó a comerciantes, habitantes y sociedad civil. Éstos defendieron el mercado y lograron ralentizar la transformación, 
enarbolando al mercado como un espacio laboral, público y de comercio tradicional y popular, contraponiéndose al intento de homogeneización de la ciudad a través de procesos de acumulación capitalista.

\section{Tendencias de la gentrificación en los mercados de Barcelona y Madrid}

Barcelona y Madrid son ciudades diferentes en muchos aspectos, quizá el fundamental para comprender sus divergencias es el proyecto de ciudad que han fomentado los cuadros políticos y técnicos en la capital catalana. Han tenido claro, por lo menos desde el restablecimiento de la democracia en Espańa, que promoverían en conjunto con la iniciativa privada una nueva ciudad aprovechando sus factores de localización, su condición costera para impulsar el turismo, así como la explotación de su historia local que enarbolaba la capitalidad de la nación catalana. Mientras que en Madrid se ha carecido de un proyecto técnico-político que guíe el desarrollo de la ciudad, replicando en no pocas ocasiones el planeamiento urbano de Barcelona. A pesar de estas circunstancias, ambas ciudades comparten características propias del urbanismo neoliberal que las están redefiniendo. Una de ellas es la recuperación de los mercados municipales y su utilización para impulsar mecanismos de especulación inmobiliaria. A continuación, se presentan los puntos convergentes en las políticas de gentrificación comercial en ambas ciudades.

\section{El deterioro como justificación}

En ambas ciudades se considera que las instalaciones de los mercados se encuentran en un avanzado estado de deterioro que demanda su inminente rehabilitación y/o reconstrucción. Sin embargo, el estado de abandono proviene de la inacción gubernamental por no brindar el mantenimiento necesario a los centros de abasto.

Asimismo, se esgrime que la oferta de productos está desactualizada, por lo que los potenciales usuarios se ausentan de estos espacios y prefieren otras modalidades de abastecimiento como los supermercados. Por lo tanto, se argumenta que debe impulsarse la "modernización” de los mercados a través de una mejora de las instalaciones, 
así como de una renovada oferta comercial. También convergen en una forma de promocionar o, mejor dicho, de crear un marketing que resalta los valores positivos de comprar en los mercados renovados, explotando el imaginario de la tradición de la que forman parte.

\section{Los mercados como impulsores de la gentrificación}

En ambas ciudades los mercados son vistos como instrumentos para impulsar procesos de gentrificación y turistificación del centro de la ciudad. Barcelona comienza con la consideración de los mercados como espacios estratégicos en los procesos de reurbanización durante la reconfiguración de la estructura de la ciudad para los Juegos Olímpicos de 1992, creando el Instituto Municipal de Mercados que se ocuparía de su gestión. Mientras que en Madrid no fue hasta 2003 que se empieza a actuar a través del Plan de Innovación y Transformación que incide en los propios mercados municipales (Ayuntamiento de Madrid, 2003).

\section{(Semi) Privatización de los mercados municipales}

En ambas ciudades se han realizado procesos de privatización que afectan tanto las reformas de las instalaciones, como la gestión e incluso la propiedad misma de los centros de abasto. Los gobiernos locales dan cada vez más protagonismo a la iniciativa privada para mantener el funcionamiento de los mercados: las reformas se realizan con financiación mixta, cediendo una importante proporción del suelo a empresas de centros comerciales que contribuyen con gran parte del presupuesto de las obras. En ambas ciudades los mercados son equipamientos públicos; sin embargo, en Madrid existe un proceso de desincorporación que ha empezado con la venta del de San Miguel, posteriormente transformado en mercado gourmet. Por otro lado, la tendencia de que el nuevo concesionario - al expirar los acuerdos de gestión con las asociaciones de comerciantes - sea una única empresa ajena al mercado representa una nueva modalidad de (semi)privatización.

\section{Implementación de marketing urbano}

Una vez renovadas las instalaciones, las campañas para crear marcas de mercado, así como para promocionarlas, asumen el protagonismo. 
De esta forma, los mercados transformados no solamente ganan más clientes, sino que asumen un liderazgo en la transferencia de conocimiento y políticas de revitalización urbana. El caso de Barcelona es un referente a nivel internacional, es por ello que lidera proyectos como MedEmporion, que promueven las buenas prácticas de una docena de ciudades del Mediterráneo, así como URBACT Markets. El branding de los mercados implica que su principal herramienta de promoción sea la creación de páginas web, así como la organización y participación en eventos de diversa índole que buscan atraer más público.

\section{Recreación y simulación}

La intervención en los mercados parte de la explotación de una visión romántica de su pasado que lleva a que sean reformados, recurriendo a elementos patrimoniales materiales y simbólicos. Lo que se puede denominar "el efecto del Mercado San Miguel" tiene cada vez más repercusión e influencia en la creación de nuevos establecimientos que representan una recreación y simulación de los mercados. Se trata de centros de gastronomía y ocio, en muchos casos privados, que recurren a la imagen antigua de los mercados para imitar su forma de organización del espacio - puestos, plaza central-, pero realmente están dedicados a la restauración y a la venta de productos gourmet que contribuyen a la creación de un nuevo imaginario de los mercadosespectáculo como espacios de ocio y de consumo de productos de alta calidad y precio.

\section{Consumo y distinción}

Tanto en Madrid como en Barcelona la revitalización de los mercados, sobre todo en el área central de las ciudades, ha implicado que los antiguos centros de abasto se vuelvan los baluartes de nuevos patrones de consumo que se engloban en la triada de lo auténtico, lo orgánico y lo natural. Éstos cada vez toman mayor relevancia en los sectores de la clase media que cuenta con suficiente poder adquisitivo y que también se configura, como diría Bourdieu (1989), en un elemento de distinción. Dichas prácticas se insertan en una escenificación del nivel 
de vida de los nuevos consumidores (Zukin, 2008), manipulando la autenticidad y construyéndola en torno a una imagen de vida sana, $y$ de consumo ético y ecológico.

\section{La política municipal respecto a los mercados públicos en Barcelona y Madrid}

\section{Barcelona}

Guàrdia (2012) señala que, a partir del restablecimiento de la democracia en Espańa, el Ayuntamiento de Barcelona comenzó a diseñar e implementar una política de mercados diferente a la que se venía desarrollando durante la dictadura. A mediados de los años ochenta se promulgó el Plan Especial de Equipamiento Comercial Alimentario de Barcelona que buscaba transformar a los mercados en un sector comercial "dinámico y moderno".

Como ya se mencionó, en el marco de la celebración de los Juegos Olímpicos de 1992 se creó el Instituto Municipal de Mercados de Barcelona, organismo autónomo que gestiona los centros de abasto y que desde entonces ha llevado a cabo la renovación de 29 de ellos; cifra que representa $67 \%$ del total de la ciudad. Se diseñaron y aplicaron una serie de medidas que buscaban la "modernización" de los mercados públicos a través de la ejecución de un nuevo sistema de administración mixta que circunscribe al gobierno la custodia de las instalaciones y las asociaciones de comerciantes se encargan de su funcionamiento, es decir, su limpieza, vigilancia y la toma de decisiones estratégicas. El modelo de administración otorga mayor injerencia a la iniciativa privada con el objetivo de hacer "competitivos" a los mercados mediante lo que el Instituto denomina la actualización de la oferta comercial y la adaptación a su entorno. En síntesis, de lo que se trataba era de "rescatar" a los mercados públicos del estado vetusto en el que se encontraban, aprovechando las oportunidades económicas que ofrecían para obtener recursos financieros y posicionar a la ciudad en el ámbito internacional.

La estrategia gubernamental en Barcelona ha consistido en reconstruir los mercados y en la medida de lo posible erradicar a los comercios 
antiguos y tradicionales que no cumplían con las nuevas directrices. Ello implica que sólo se mantengan los negocios más competitivos que se han adaptado a los nuevos patrones de consumo de la población que vive y visita la ciudad.

Los planes de modernización de los mercados públicos se han diseñado e implementado desde tres dimensiones complementarias. En primer lugar, la reforma y remodelación de los edificios de los mercados; en segundo lugar, el diseño de proyectos para la profesionalización de la gestión y, por último, acciones de marketing y promoción.

Para lograr la remodelación de los mercados el Ayuntamiento de Barcelona adoptó un modelo de financiación mixta donde la cantidad máxima aportada por la administración es de 50\% de los fondos necesarios (IMMB, 2014), mientras que el resto se recauda de los comerciantes e ingresos por nuevas licencias otorgadas. En el marco de este modelo de colaboración público-privada, algunas empresas sufragan parte de las obras con el objetivo de instalarse en los mercados renovados en forma de supermercados, restaurantes y tiendas gourmet, entre otros. Esto implica una reordenación de los puestos existentes y su reducción con el argumento de que se trata de una optimización del servicio que contribuiría a la sostenibilidad económica del conjunto del mercado. Asimismo, con el objetivo de aprovechar la ubicación central y el valor patrimonial de los edificios de algunos mercados - Sant Antoni y Santa Caterina, en particular-, su rehabilitación se diseñó a partir de acciones de embellecimiento, museificación y arquitecturaespectáculo que les convertirían en iconos turísticos.

Las reformas no se limitan al entorno construido, sino también buscan transformar la relación de los comerciantes con el mercado, instándolos a adoptar la posición de emprendedores, gestores e inversores y compaginarla con su papel de "guardianes de la tradición y la proximidad”. Desde el Instituto Municipal de Mercados se apuesta por una formación en gestión, marketing y uso de nuevas tecnologías, como parte de la eficiencia empresarial a la que se aspira. También existe una presión continua de ampliar horarios y renovar la oferta comercial, con especial énfasis en productos locales y/o ecológicos. Finalmente, se busca implicar a los comerciantes en la financiación de las reformas. El 
requisito de contribuir con una parte de la financiación necesaria para las obras podría significar el desplazamiento de las personas que no pueden permitirse invertir en ello.

La promoción de los mercados renovados a través de campañas publicitarias, creación y difusión de contenido en las redes sociales y organización de eventos, es parte fundamental de la estrategia de atracción de un público nuevo. El actual Plan Estratégico de Mercados 2015-2025 apuesta por ferias temáticas de gastronomía, aumento del espacio destinado a degustación y eventos de showcooking, reconociendo el papel del Mercado de San Miguel —analizado más adelante- como modelo a seguir. También destaca el interés hacia el uso de nuevas tecnologías para la administración y gestión de los mercados, que forma parte de la aspiración de Barcelona a posicionarse como smart city. El Plan considera que es necesario integrar plataformas y prácticas de smart commerce no sólo como forma de aumentar la eficiencia y rentabilidad, sino también como una manera de mejorar la experiencia de los consumidores.

La trayectoria de Barcelona ha sido de tal importancia a nivel internacional que la ha llevado a liderar el proyecto URBACT Markets, financiado por la Unión Europea, en el cual participan diez países de ésta. La finalidad del programa, como puede verse en su portal web, consiste en replicar las prácticas de la capital catalana en cuanto a los mercados como "motores para promover el empleo y a los emprendedores, la regeneración urbana y la sostenibilidad”. Cabría señalar que esta serie de términos proviene de lo que Harvey (1989) denomina el "empresarialismo urbano", utilizado por los gobiernos para incentivar la mercantilización de la ciudad, misma que beneficia a los poderes financieros y excluye a los menos favorecidos. La difusión del modelo de mercados de Barcelona a través de acciones de consultoría internacional es un proyecto de liderazgo a largo plazo que se refleja en el Plan Estratégico para el Desarrollo de los Mercados durante la siguiente década.

\section{Madrid}

El Ayuntamiento de Madrid también ha desarrollado una política pú- 
blica para recuperar sus mercados municipales, destacando tres grandes acciones que han hecho posible la transformación de cada vez más mercados en centros de ocio y gastronomía o en complementos comerciales a un supermercado que ocupa gran parte de la superficie antes dedicada al pequeño comercio.

La primera de estas acciones es la ejecución del Plan de Innovación y Transformación de los Mercados Municipales de Madrid, cuyos objetivos consistieron en reformar la infraestructura, profesionalizar y mejorar la gestión, así como realizar una campaña de promoción y marketing. El Plan se inició en 2003 y hasta 2011 se realizaron obras de rehabilitación en 39 de los 46 mercados municipales, es decir, 84\%. Éstas frecuentemente se han efectuado con la ayuda de financiación externa proveniente de empresas de supermercados que, a cambio de asumir gran parte de los costes de la reforma, obtuvieron la cesión de espacio para sus tiendas dentro de los mercados. Este tipo de cooperación público-privada tiene un carácter contradictorio. Aunque a corto plazo es posible que la presencia de supermercados aumente la afluencia de clientes en los edificios reformados, la competencia que ejercen las medianas superficies a los puestos del mercado es desigual. El Plan, considerado un éxito, fue prolongado para el periodo 2012-2015, con énfasis en el marketing y la publicidad de la Marca Mercados.

La segunda acción ha consistido en aprobar cambios en la normativa que rige el funcionamiento de los mercados y permite la introducción de nuevos tipos de negocios, reduciendo el porcentaje de superficie que debe destinarse a comercio de alimentos de 65\% a 35\% (Ayuntamiento de Madrid, 2014), y estableciendo que hasta $40 \%$ del espacio común podría ser usado para eventos, como degustaciones, sin que sea necesario pedir una licencia de esta nueva actividad. ${ }^{5}$ La mencionada herramienta legal propicia la reorganización de los puestos de los mercados en una parte "tradicional" y otra "innovadora", y el paulatino desplazamiento de los puestos de venta de productos de alimentación en favor de espacios de restauración y tiendas gourmet que resultan mucho más rentables.

La última, y principal diferencia con la gestión de los mercados de

\footnotetext{
${ }^{5}$ Ordenanza de dinamización de actividades comerciales en dominio público 2014.
} 
Barcelona, consiste en la implementación de un modelo de privatización de los mercados municipales. Así, se otorgan las concesiones recién expiradas de varios mercados a organismos privados, frecuentemente de constitución reciente y titularidad unipersonal, que no tienen vinculación previa con los mercados ni experiencia en su gestión. De esta forma, las asociaciones de comerciantes que tradicionalmente han sido las concesionarias sufren una pérdida de poder de decisión y se convierten en simples inquilinos.

Las transformaciones de los mercados se inscriben en los planes de desarrollo de la ciudad que apuestan por una imagen de Madrid competitiva y de proyección internacional. A diferencia de Barcelona, se han aprobado proyectos municipales como Madrid Centro, el Plan de implantación del centro comercial abierto Plaza Mayor o el Plan integral de apoyo a la competitividad del comercio minorista (Ayuntamiento de Madrid, 2008), que adquieren narrativas propias del urbanismo neoliberal que apuesta por reconfigurar la ciudad a través de la creación de business improvement districts, es decir, centros comerciales a cielo abierto y ejes comerciales descritos como espacios de innovación y creatividad que incluyen a los mercados como posibles motores dinamizadores de la transformación de la ciudad. Sin embargo, hasta el momento sólo se han quedado en propósitos y su implementación se ha visto dificultada por cuestiones coyunturales.

\section{Mercados-museo y turismo}

En el actual contexto urbano de competitividad global los centros históricos resultan espacios de singular importancia y la actividad turística cobra mayor relevancia como generadora de ingresos para las ciudades. Judd (2003) menciona que la herencia arquitectónica y cultural de los núcleos urbanos ha sido entendida como la principal atracción para los visitantes, por lo que las actividades turísticas se han enfocado a realzar el carácter de esa zona de la urbe. Ello produce efectos sobre el espacio urbano como el incremento del valor del suelo, la modificación del mercado habitacional, el cambio en la estructura comercial y la llegada de personas de diversas latitudes. Los centros históricos españoles se inscriben en esta dinámica que se ha potenciado 
especialmente en Barcelona y Madrid durante los últimos años. Los Mercados de La Boquería y de San Miguel son dos paradigmas de este tipo de manifestaciones.

La turistificación del centro de las ciudades tiene múltiples implicaciones socio-espaciales. Si el proceso de gentrificación se caracteriza por atraer a población de mayores recursos y con un estilo de vida diferente que sustituye a los antiguos habitantes de clases bajas, el turismo trae población flotante que transita y consume en la zona. Sus estancias son cortas, y en muy pocas ocasiones se implican en la vida cotidiana del lugar que visitan. Por lo tanto, a medio y largo plazo, las transformaciones provocadas por la creciente popularización de los pisos turísticos y por las modificaciones de servicios y productos ofrecidos podrían tener consecuencias graves para los vecinos de menores ingresos del barrio, debido a que experimentarían procesos de tematización, teniendo como efecto el desplazamiento.

A diferencia de las ciudades estadounidenses en las que el turismo urbano se caracteriza por la fragmentación y segregación espacial a partir de una arquitectura insular que garantiza la seguridad, en las ciudades europeas los visitantes tienden a ser absorbidos en su trama urbana (Judd, 2003). El turista busca jugar un doble papel: intentar comportarse como un habitante, sin dejar de perder las (des) ventajas de foráneo; en otras palabras, busca moverse entre el adentro y el afuera. De esta forma, pretende vivir y experimentar las experiencias de una persona local, y para ello ya no sólo asiste a los iconos turísticos tradicionales como museos, monumentos y bares o restaurantes emblemáticos, sino que además va en búsqueda de explorar "terras incognitaes" en las que podría satisfacer sus demandas de cotidianidad y autenticidad. En este sentido, los mercados municipales se erigen como espacios cotidianos que en teoría representan el acercamiento con la cultura local, pero los cuales han ido perdiendo ese carácter debido a las políticas públicas implementadas por los gobiernos locales justamente a través del proceso de turistificación. Éstas justamente tienden a convertir los mercados en iconos turísticos, pero sin dejar de ser puestos al servicio de las clases medias atraídas por el proceso de gentrificación que viven los barrios centrales, como ocurre en Barcelona con el Mercado de 
Santa Caterina (Hernández, 2014). Locales y foráneos conviven en un mismo espacio mediante patrones de consumo de bienes materiales y simbólicos que hallan en los mercados municipales, así como estilos de vida que buscan la autenticidad como valor fundamental. De esta forma, como lo señalan varios autores (Hiernaux y González, 2014; Judd, 2003), hay cada vez más evidencias de similitudes entre turistas y autóctonos en las prácticas de consumo, así como en las formas de habitar la ciudad.

Los mercados transformados contribuyen al fomento de la economía del ocio y restauración en su zona de influencia, revalorizando su entorno que empieza a ser deseable para estar — por lo tanto, comienzan a proliferar terrazas, bares, tiendas, hoteles, apartamentos turísticos-. No es una situación estática, sino que el turismo y la construcción del centro urbano como un parque temático crea un efecto llamada de productos cada vez más sofisticados y originales en los mercados.

\section{Mercado de La Boquería}

La Boquería, ubicado en el centro de Barcelona, se ha convertido en un icono turístico de la ciudad por su valor patrimonial tanto arquitectónico como inmaterial que lo ha llevado a ser reconocido como el "Mejor Mercado del mundo" según el Congreso Mundial de Mercados en 2005. Su transformación se intensificó a partir del boom turístico que experimentó Barcelona después de la realización de los Juegos Olímpicos de 1992. Según el Consorcio de Turismo de Barcelona (2013) en el periodo de 1993 a 2013 el número de visitantes que recibió la ciudad se triplicó acogiendo a 100 millones de turistas en total.

El crecimiento del turismo tuvo un gran impacto sobre La Boqueria, dado que el mercado tiene una ubicación privilegiada en un lateral del paseo de la Rambla. El mercado se ha integrado en el trayecto que realizan por la calle los visitantes extranjeros y/o espańoles que representa uno de los principales ejes turísticos de la ciudad. La Asociación Amigos de la Rambla seńala en su portal electrónico que cerca de 78 millones de personas transitan por las Ramblas al año —una media de 213,000 al día-, lo cual puede darnos una idea sobre el crecimiento 
de visitantes que ha experimentado el mercado.

La remodelación de La Boquería se inició en 1998 y supuso una reorganización del espacio, se amplió la superficie del mercado que incluyó la instalación de un restaurante y la supresión de puestos informales que se ubicaban en los alrededores. El objetivo consistían en revalorar la arquitectura de La Boquería como un atractivo del mercado y de la ciudad. La transformación del Mercado se completó con la progresiva instalación de bares y restaurantes al interior del recinto, tanto en las calles adyacentes.

Hasta la década de los noventa, el mercado se caracterizó por ofrecer una amplia variedad de alimentos locales y foráneos a precios relativamente asequibles, esta situación lo había posicionado como el centro de abasto más destacado de la ciudad. Además, contaba con bares que ofrecían una gastronomía popular y particular. La combinación de productos alimenticios y gastronómicos llevó a que La Boquería fuera denominada por el gran escritor barcelonés Vázquez Montalbán (2001) como "la Catedral de los sentidos", en la que se encontraban marchantes y sibaritas.

El Mercado experimentó un cambio en los patrones de consumo que está llevando a la desaparición progresiva de los comercios de alimentos básicos, dado que la mayoría de los visitantes son turistas que demandan otro tipo de productos. Actualmente, los locales comerciales ofrecen alimentos preparados para su degustación al momento, así como vasos y canastillas de plástico con coloridas frutas, y caramelos y chocolates. Además, los bares del Mercado cada vez se han ido sofisticando más en su oferta. Esta situación ha generado que los vecinos y consumidores comunes se sientan excluidos de su antiguo Mercado. Mientras que en el ámbito de los comerciantes existe un conflicto debido a que una parte de esta situación representa la oportunidad de dar un giro comercial y/o traspasar su establecimiento con el propósito de obtener beneficios económicos. Por otra parte, un sector de vendedores se siente amenazado debido a la proliferación de establecimientos de "comida para llevar", pues lleva a la reducción de su clientela, así como por la masificación turística, que considera negativa, y el incremento en el valor del suelo. 


\section{Mercado de San Miguel}

El Mercado de San Miguel, ubicado en el centro histórico de Madrid, está sentando un precedente en cuanto a la transformación de un mercado tradicional en un centro gourmet, a través del uso de herramientas legales, de la apropiación de imaginarios y prácticas tradicionales y, al mismo tiempo, mediante discursos de modernización y vanguardia.

En una entrevista con el periódico El País (en su edición de 25 de octubre de 2005), Montserrat Valle, la presidenta de la empresa que adquirió el Mercado de San Miguel señala que en un principio se intentó reproducir la experiencia de La Boquería. Sin embargo, la renovación fue más allá de puestos tradicionales con productos de atractivo turístico listos para consumir. $\mathrm{Al}$ mismo tiempo que mantiene un discurso de rescate del patrimonio y recuperación de la tradición, la empresa propietaria literalmente vació el Mercado del contenido que tuvo durante décadas, una de las implicaciones socio-espaciales más importantes de la gentrificación (Franquesa, 2007). Solamente uno de los puestos tradicionales resiste la renovación, el resto ofrece productos para consumir al momento que evocan una autenticidad local y, a la vez, una dimensión cosmopolita, dedicados claramente a un público de alto poder adquisitivo. Se trata de una construcción de lo local y lo auténtico como experiencia que atraiga a los turistas en su búsqueda de lo extraordinario y lo nuevo, pero que al mismo tiempo sea típico del lugar visitado.

La concentración de la propiedad en manos de una sola empresa ha permitido llevar a cabo el proyecto de transformación de San Miguel en un "templo gourmet". Se trata de un ejemplo claro de desplazamiento donde el discurso de crecimiento económico a través del turismo y la promoción de una cultura gastronómica legitiman la desaparición del Mercado tradicional. La remodelación redujo el número de puestos a la mitad - de 75 a 33- y liberó el espacio central del recinto para la organización de eventos y degustaciones.

Aunque se trata de un Mercado privado, la colaboración de la administración pública ha sido esencial. Las modificaciones en la legislación, la inclusión del mercado en planes de revitalización del centro, 
la financiación obtenida de fondos públicos y al apoyo manifiesto del gobierno de la ciudad a este nuevo concepto de mercado hicieron posible la transformación de San Miguel.

Los Mercados de La Boquería y de San Miguel se han vuelto potentes referentes urbanos que son explotados por la economía local y que han implicado trasformaciones en su entorno inmediato, pero sobre todo en la forma de entender y gestionar el consumo en la ciudad. Ambos centros de abasto fluctúan entre ser templos gourmets o museos en lo que tanto los turistas como las clases medias a través del consumo buscan la distinción (Bourdieu, 1989). El antropólogo Delgado (2014) señala en su blog que los mercados se vuelven grandes barras de pinchos, cervezas artesanales, postres, en donde estos sectores sociales acuden a venerar, observar y probar objetos que aunque comestibles son igualmente museificados. El mismo autor sostiene que, así como la cultura sirve para diferenciar a las "personas civilizadas", también la gastronomía desempeña un papel similar y diversificar los cánones del consumo de clase media. La tematización del espacio reduce la complejidad que se expresa a través de la invención y puesta en escena de lo tradicional en cuanto a comida y/o uso del espacio que genera experiencias auténticas y pintorescas.

\section{Mercados-malls y la gentrificación}

Otro tipo de transformación que experimentan algunos mercados públicos, y que también está vinculada con la tematización de la ciudad, es su conversión en centros comerciales. Se debe recordar que el objetivo inicial de estos establecimientos consistía en cubrir las necesidades básicas de las familias suburbanas (López de Lucio, 2002), pero se ha ido transformando con cada vez más productos y servicios. Los malls se han convertido en gigantescos complejos de entretenimiento en los que el ocio equivale a consumo y donde los pasillos y plazas crean una falsa imagen de espacio público que, sin embargo, es de gestión y control privado, siendo la empresa propietaria la que determina las normas de acceso y uso.

Coincidimos con Bravo y Porretta (2009) cuando mencionan que las características de adecuación de los mercados tienen que ver con 
el modelo de centro comercial del extrarradio de la ciudad. Para ellos es paradójico que para reformar los mercados se utilice la forma de las tiendas de autoservicio, la cual se inspiró en la vida urbana de los mercados de los áreas centrales.

Los mercados municipales en la actualidad pretenden asumirse como malls y existen varias coincidencias que nos hacen pensar en esta dirección. Por un lado, y quizá la más obvia, es la apertura de hipermercados en instalaciones de los equipamientos municipales, esgrimiendo que el costo de las operaciones de reforma se financia en parte con la concesión a las cadenas de supermercado. Esta situación genera un riesgo para los comerciantes, a quienes les resulta complicado competir con los precios de las cadenas que adquieren sus mercancías por grandes volúmenes. Por otro lado, se tiende a que dichas reformas tengan como objetivo construir iconos arquitectónicos, monumentalizando los edificios para que resulten más atractivos a los visitantes. Asimismo, a los mercados se les dota de una serie de amenidades típicas de los centros comerciales como climatización, instalación de escaleras eléctricas, iluminación artificial y la adecuación de los escaparates, mientras que la liberalización de los usos del espacio para nuevas actividades los convierte en una oportunidad de inversión para toda clase de empresas que buscan un espacio de grandes dimensiones con ubicación central. De esta manera, asistimos a una convivencia inusual entre fruterías, carnicerías, escuelas de baile, gimnasios... Esta transformación del espacio material y de los tipos de negocios, de los productos que ofrecen, y el público al que están destinados, hace que se pierda la función primordial de los mercados, convirtiéndolos en espacios de ocio, recreación y consumo a semejanza de los malls.

\section{Mercado de Santa Caterina}

El Mercado de Santa Caterina tiene su origen en el siglo XVIII. $\mathrm{Y}$ en el siglo XX se erigió como uno de los principales centros de abasto de la ciudad. En los años 80, con la transición política y la efervescencia de los movimientos ciudadanos en Barcelona, los vecinos del barrio plantearon su reconstrucción ante el deterioro en 
que se encontraba. Esta idea fue recogida por el Ayuntamiento de Barcelona y en 1999 comenzaron las obras de reforma a partir del proyecto de los connotados arquitectos Enric Miralles y Benedetta Tagliabue. La remodelación del Mercado de Santa Caterina supuso, junto con la apertura de la avenida Cambó, la pieza central de la reordenación y la revitalización social y comercial de uno de los barrios más emblemáticos de la ciudad.

El proyecto se estructuró en torno a seis actuaciones: el Mercado, la preservación de los restos arqueológicos encontrados en el subsuelo, la urbanización del entorno, la construcción de viviendas de protección oficial para personas mayores, un aparcamiento, y una central de recogida neumática de basura. El Mercado fue totalmente rehabilitado, sólo se mantuvieron tres de sus antiguas fachadas y su nuevo elemento distintivo pasó a ser la gran cubierta ondulada de mosaicos coloridos que reposa sobre una estructura de grandes arcos de metal y madera que generan olas asimétricas.

El nuevo proyecto de reconstrucción del Mercado de Santa Caterina se tradujo en una reducción de los negocios y una escenografía aséptica de escaparates bien iluminados que no tenía nada que ver con el estado de los últimos años del equipamiento. De esta forma, la nueva imagen del antiguo centro de abasto popular se asemejaba más a la de centro comercial en donde todo es reluciente y controlado.

En el espacio dejado por los comerciantes que se jubilaron o que no pudieron pagar el precio de la reforma se abrió un restaurante que con su alquiler ayudaría a cubrir los costes de la reforma. La instalación de este nuevo establecimiento con decorado minimalista y con una carta de alimentos autodenominada cuina de mercat ofrece una tematización de la experiencia del Mercado. De esta forma, se ofrecen los elementos típicos pero de una forma sofisticada y aséptica que por sus precios sólo es posible para los nuevos residentes del barrio y los turistas.

El elemento de mayor impacto en la transfiguración del Mercado fue la instalación en el subsuelo de una tienda de autoservicio y un aparcamiento. Éstos se instalaron bajo la lógica de que deberían financiar las costosas obras de reconstrucción, además de que se consideraba que 
el formato comercial de los mercados municipales estaba caducado y que se debía de agregar un supermercado para complementar la oferta comercial, es decir, que en el centro de abasto se podrían encontrar productos frescos y también no perecederos.

El nuevo modelo de gestión del Mercado de Santa Caterina, la renovada oferta comercial, la espectacular cubierta ondulada y el área arqueológica habilitada, lo hace un sitio totalmente nuevo. El Mercado resulta atractivo para los nuevos habitantes del barrio y en general para los barceloneses y los turistas porque concentra una oferta comercial, opciones de ocio, así como un paisaje pintoresco y auténtico enmarcado en la arquitectura espectáculo. Sin embargo, han resultado excluidos los vecinos de rentas bajas, debido a los precios elevados de los productos, quienes antiguamente eran los principales clientes del Mercado.

\section{Mercado de San Antón}

Otro ejemplo de Mercado-mall es el de San Antón, que se ubica en el barrio de Chueca en Madrid. La transformación del Mercado es paralela a la del barrio que pasó por décadas de abandono y desinversión que conllevaron a una pérdida de población, degradación de la infraestructura y estigmatización de la zona. La influencia de habitantes y empresarios gays en la paulatina transformación de Chueca está relacionada no sólo con transformaciones materiales - apertura de tiendas y locales de ocio destinados a esta comunidad-, sino también con cambios demográficos y de modelos de consumo. El barrio se caracteriza cada vez más por la presencia de unidades unifamiliares o parejas jóvenes sin hijos y un gran número de profesionales con una formación e ingresos altos. Las preferencias de consumo de este tipo de población afectaron profundamente el tipo de comercio en el barrio (Boivin, 2012). La interrelación entre la llegada de nuevos habitantes, de perfil profesional y nivel adquisitivo más alto, así como la “pacificación” y elitización del ocio y consumo en la zona, ilustran la interdependencia entre gentrificación residencial y comercial, que actualmente tiene unos de los precios de alquiler más altos de la zona centro de Madrid.

La transformación de San Antón fue promovida por algunos de los comerciantes, lo cual refleja las distintas visiones e intereses dentro 
del Mercado donde los vendedores no son un grupo homogéneo de personas con aspiraciones comunes. Mientras una parte de ellos/as no pudo preservar su puesto en el Mercado renovado - las paradas se redujeron de 38 a 25- y aceptó retirarse a cambio de una indemnización, otra parte transformó sus negocios o los alquiló. El Mercado fue derribado en 2007 y en su lugar se construyó un nuevo edificio que fue financiado por el Plan de Innovación y Transformación de los Mercados Municipales, aunque la mayor parte del coste la asumió el supermercado que ocupó la planta inferior. En el marco de la tendencia de este tipo de financiación a cambio de coexistencia, San Antón es el único Mercado en Madrid donde hay una tienda de autoservicio de la cadena Supercor, cuyos precios suelen estar por encima de la media en el sector, algo que concuerda con la llegada de población de altos ingresos. El supermercado cuenta con entrada independiente y aparcamiento, una característica habitual de los malls donde las zonas de compra cotidiana, de tiendas, y el espacio de ocio y restauración, suelen estar separados.

La zona de "Mercado tradicional", ubicada en la primera planta, se caracteriza por una estética aséptica y reluciente de forma similar al de Santa Caterina. Tanto la distribución de los espacios como la renovada oferta comercial representan una ruptura con el modelo anterior de mercado de abastos. Los puestos están separados entre sí por barreras que forman una especie de laberinto y cada tienda tiene el derecho exclusivo de ofrecer un determinado tipo de productos. Así, hay sólo una frutería, carnicería, etc., con el objetivo de evitar una competencia que siempre ha sido característica de los mercados.

El espacio de restauración y ocio es el auténtico protagonista del mismo. Los distintos puestos de comida preparada para llevar o para degustar ocupan toda una planta y son el principal reclamo para un público nuevo que busca variedad de experiencias gastronómicas concentradas en un solo espacio. Se puede elegir entre los múltiples puestos de tapas con toques cosmopolitas, el restaurante con amplia terraza y vistas a los tejados del centro de Madrid o la visita a los eventos y exposiciones gastronómicas que se suelen organizar en el Centro Cultural de Arte Emergente que existe en el Mercado. 
Los casos de Santa Caterina y San Antón muestran la forma en que los mercados municipales que representaban la antítesis de los centros comerciales tienden cada vez más a parecerse a ellos. Todo indica que esta conversión representa el avance del modelo de ciudad economicista que busca aprovechar a los viejos equipamientos como sitios de alto interés monetario, pero que además elimina su función y simbolismo como espacios públicos que se constituyen a través de relaciones de vecindad, proximidad y convivencia. De esta forma, siguiendo a Robles (2008), se puede argumentar que los mercados están en riesgo de perder su característica de lugar de encuentro en el cual las personas están, conversan y cristalizan relaciones e intercambios de reciprocidad y redistribución comercial y cultural, imponiendo relaciones sociales de tránsito, anónimas e interpersonales que predominan en los grandes centros comerciales. De esta manera, como sentencian Bravo y Porretta (2009), los mercados progresivamente se están convirtiendo en espacios privatizados y "lo único que quedará del antiguo mercado será la imagen de espacio tradicional, pero vaciado de todo sentido".

Sin embargo, el discurso que producen los mercados transformados sobre sí mismos indica el valor del capital "tradicional" del que intentan apropiarse. En la página web del de San Antón se pueden encontrar múltiples descripciones de los puestos que se refieren a sí mismos como tradicionales e intentan inscribirse en una autenticidad de mercado que en la realidad destruyen. Por otra parte, es significativo que el espacio cultural del mercado albergue actualmente una exposición sobre gentrificación. La elección precisamente de este lugar por el artista podría responder tanto al uso cada vez más frecuente y fuera de los círculos académicos del concepto de gentrificación, como a una toma de conciencia en cuanto al arte y la cultura como impulsores de las transformaciones urbanas y el papel que juegan en ellas actores que tienen una postura crítica con la gentrificación, pero al mismo tiempo participan en prácticas que contribuyen a su avance.

\section{Reflexiones finales}

Las transformaciones contemporáneas en el espacio urbano tienen 
como uno de sus protagonistas a los mercados municipales, Barcelona y Madrid son ejemplos de este fenómeno. Los mercados en las últimas tres décadas han experimentado una importante mutación que los ha llevado a transitar de su función de centros de abasto para los sectores menos favorecidos a erigirse como espacios de consumo para grupos de mayores ingresos. Los principales agentes que lideran esta mutación son los gobiernos municipales que buscan hacer sus ciudades más llamativas para la atracción de flujos de capitales y personas. El cambio no sería posible sin el respaldo de la iniciativa privada que se beneficia de las operaciones de reforma urbanística, así como de la posterior gestión de los mercados.

Barcelona ha sido la ciudad referente en España en cuanto a transformación urbana en el ámbito de los mercados municipales. El "modelo de Mercados de Barcelona" ha sido reproducido a escala nacional e internacional a través de lo que González (2011) denomina policy tourism, es decir, visitas de técnicos, políticos, expertos o emprendedores destinadas al estudio y posible reproducción de políticas consideradas exitosas en la regeneración urbana. Sin embargo, en su proceso de transferencia a otros contextos, el modelo se transforma y reinventa, convirtiéndose a su vez en objeto de imitación. Es el caso de Madrid, donde el Mercado de San Miguel en un primer momento se inspiró en el de La Boquería, pero realmente sufrió una mutación más intensa. Actualmente ambos actúan como modelos paralelos para otros mercados.

Los casos analizados en Barcelona y Madrid muestran que convergen en directrices de transformación urbana y comercial:

La tendencia de convertir a los mercados en museos y templos gourmet, aprovechando su localización en los cascos históricos, así como el valor arquitectónico de sus propios edificios y la oferta de productos gourmets y singulares. Ello ha generado la tematización de los mercados que se han vuelto sobre todo nodos de atracción turística, así como espacios de distinción para las clases medias.

La propensión a que los centros de abasto se conviertan en mer- 
cados-mall implica la reconversión de su estructura física, pero también una profunda trasformación en el nivel de las relaciones sociales, ocasionando la pérdida de los vínculos de proximidad social que caracterizan a los mercados. El mercado-mall se vincula con procesos de gentrificación, contribuyendo al reforzamiento del estilo de vida de la clase media e involucrando procesos de desplazamiento para los antiguos vecinos.

Las tendencias mencionadas muestran los diferentes procesos que experimentan los mercados que son guiados por fenómenos de especulación inmobiliaria que acarrean consecuencias para los menos favorecidos. Los habitantes de mayores ingresos son los que tienen la capacidad económica para poder adquirir productos en los nuevos mercados, disfrutando de una vida barrial basada en el consumo y la distinción. Mientras que los vecinos y comerciantes de rentas bajas son los menos favorecidos porque experimentan un proceso de exclusión socio-espacial. La recuperación de los mercados se puede interpretar, desde el "revanchismo urbano" (Smith, 2001), como la manera en que se pretende suprimir a las clases populares en estos recintos y recuperar equipamientos con un alto potencial económico para instituir una ciudad aséptica, temática y económicamente rentable.

\section{Epílogo}

Finalmente queremos hacer un llamado de atención a partir de la última reflexión que se centra en los mercados que se hallan en una fase decisiva de su metamorfosis y que se utilizan como impulsores de procesos de transformación urbana. Los casos a los que nos referimos se encuentran en los límites de los centros históricos de Barcelona y Madrid. Su ubicación fronteriza los llevaría a poder entenderse, según González y Waley (2012), como el "avance de la frontera urbana" de la gentrificación. Sin embargo, aquí se considera que más que actuar como una avanzada de la transformación, los centros de abasto se erigen como los "caballos de Troya" del proceso de gentrificación.

\footnotetext{
${ }^{6}$ Se retoma esta idea que aportó el antropólogo José Mansilla en el debate del Semina- 
Los mercados, al funcionar como espacios de centralidad comercial y social, desempeñan un papel determinante en la vida barrial. Cuando son transformados en muchas ocasiones se trastoca el corazón del barrio, impulsando mutaciones urbanas que tienen un efecto en cadena sobre éste.

Un primer ejemplo es el Mercado de Sant Antoni en Barcelona, que se sitúa en el borde del ensanche barcelonés con el centro histórico de la ciudad. Hasta hace no mucho era considerado como La Boquería de los pobres (Vázquez Montalbán, 2001) por ser frecuentado por sectores menos favorecidos. En 2009 iniciaron las obras de reconstrucción, con lo cual fue cerrado, y los comerciantes fueron trasladados a carpas provisionales instaladas al costado del centro de abasto. Hasta el momento se está llevando su proceso de reconstrucción que incluye la restauración de la estructura de hierro considerada de valor patrimonial, la instalación de un supermercado y la museificación de una parte a través de la exposición de la vieja muralla de la ciudad.

La transformación del Mercado ha sido paralela a la progresiva revalorización del barrio en el que se encuentra, pues en los últimos años ha experimentado un cambio tanto de población con la llegada de habitantes de mayores ingresos como de la estructura comercial, que cada vez tiende más hacia la presencia de restaurantes gourmets y boutiques. Asimismo, se están ejecutando trabajos complementarios en las fachadas de los edificios circundantes e incluso alguna finca contigua ha sido adquirida por un fondo de inversión global — BMB Investment Management- que vende los departamentos renovados en por lo menos medio millón de euros, precio que se sitúa por encima de la media del barrio. Si la tendencia continúa, la apertura del mercado en 2016 contribuirá a intensificar el proceso de revalorización iniciado hace tiempo en Sant Antoni.

Otro Mercado en riesgo es el de los Mostenses en Madrid, que también se encuentra en una posición fronteriza: en el centro, pero a espaldas de la Gran Vía, quedándose al margen tanto de grandes operaciones de remodelación que han afectado a su entorno, como del

rio Contested Cities realizado en diciembre de 2013, en Madrid, España. 
Plan de Innovación y Transformación, del que no ha recibido fondos. Sin embargo, sí existe interés por parte de inversores privados, como el grupo Triball, para financiar una reforma, proponiendo construir una planta superior dedicada a la restauración a cambio de la cesión de los derechos de uso de este nuevo espacio. Aunque el proyecto está temporalmente congelado resulta significativa la forma en la que la desinversión por parte de la administración deja espacio para una privatización del Mercado.

El proyecto de Triball es representativo para la zona en la que se encuentra el Mercado, ya que un tipo de actuación similar se estállevando a cabo en distintos edificios de los alrededores. La remodelación de la Plaza de España, el derribo o vaciamiento de edificios en su perímetro para su conversión en hoteles de lujo, demuestra el nulo valor que se da tanto al patrimonio, como a los usos cotidianos del barrio por los vecinos, intentando fomentar el desarrollo de la zona como un nuevo enclave turístico.

El aspecto y uso actual de los Mostenses, sin embargo, contrastan con esta idea. Las pocas mejoras realizadas en la infraestructura fueron financiadas por los comerciantes y los productos que se pueden encontrar en el Mercado son alimentos de primera necesidad y uso cotidiano. Un rasgo característico es la presencia, todavía poco común en los mercados de Madrid, de un gran número de comerciantes de origen extranjero y de productos étnicos que suelen tener precios económicos.

El Mercado de Sant Antoni y el de los Mostenses contrastan con los centros de abasto analizados en el cuerpo de este trabajo en su estado físico y en su localización periférica de los centros históricos de sus respectivas ciudades. Su inminente remodelación y gentrificación evidencian que los gobiernos locales y la iniciativa privada encuentran en estos viejos equipamientos oportunidades de impulsar procesos de transformación urbanística y de especulación inmobiliaria en zonas estratégicas de la ciudad. Ambos mercados se encuentran en un proceso de transición que permite que sus prácticas cotidianas de intercambio social y económico aún no estén estetizadas. Hacer ruido, poder tocar la mercancía, exponer a la venta los productos sin empaquetar, siguiendo a Marovelli (2014), representa una des- 
obediencia a la tendencia del mercado embellecido que se promueve desde las autoridades como forma de negocio rentable y como parte de una ciudad domesticada.

Ambos mercados aún mantienen un carácter popular que en sí mismo resulta contestatario a las lógicas neoliberales. Estos equipamientos son espacios estratégicos para impulsar procesos de turistificación y gentrificación, aunque su futuro aún es incierto.

\section{Bibliografía citada}

Alonso, Roberto, 2008, "Modernización de los mercados municipales minoristas, servicio público y eficiencia empresarial", en $E l p a-$ pel de Mercasa. Distribución y consumo, núm. 100, pp. 168-174. Ayuntamiento de Barcelona, 2004, Plan Municipal de Mercados 20042007, Barcelona, España.

Ayuntamiento de Madrid, 2003, Plan municipal de innovación y transformación de los mercados de Madrid 2003-2011, Madrid, España.

Ayuntamiento de Madrid, 2008, Plan de implantación del centro comercial abierto Plaza Mayor 2008, Madrid, España.

Ayuntamiento de Madrid, 2014, Ordenanza de dinamización de actividades comerciales en dominio público 2014, Madrid, España.

Boivin, Renaud, 2012, "Rehabilitación urbana y gentrificación en el barrio de Chueca: la contribución gay", en Revista LatinoAmericana de Geografia e Gênero, núm 1, pp. 114-124.

Boldrini, Paula y Matilde Malizia, 2014, "Procesos de gentrificación y contragentrificación. Los mercados de Abasto y del Norte en el Gran San Miguel de Tucumán (noroeste argentino)", en INVI, núm. 81, pp. 157-191.

Bourdieu, Pierre, 1989, La distinción. Criterio y bases sociales del gusto, Taurus, Madrid.

Bravo, David y Daniele Porretta, 2009, "Elegía por los mercados de Barcelona”, en Masala, núm. 49.

Bridge, Gary \& Robin Dowling, 2001, "Microgeographies of retailing and gentrification", en Australian Geographer, núm. 32, pp. 


\section{3-107.}

Consorcio de Turismo de Barcelona, "Barcelona recibe 100 millones de turistas en 20 años", Nota de prensa, Barcelona, 13 de noviembre de 2013, disponible en http://professional.barcelonaturisme. com/files/8684-1033-pdf/Barcelona $\% 20$ recibe\%20100\%20 millones\%20de\%20turistas\%2020\%20a\%C3\%B1 os\%20 de\%20Turisme\%20de\%20Barcelona.pdf [consultado en línea el 2 de octubre de 2014].

Deener, Andrew, 2007, "Commerce as the structure and symbol of neighborhood life: reshaping the meaning of community in Venice, California”, en City \& Community, núm. 6, pp. 291-314.

Delgado, Manuel, 2014, "Jerarquización por rango de autenticidad de los espacios de un mercado "tradicional" en un pueblo de la comarca de Goierri", El cor de las aparences. Blog de Manuel Delgado, Barcelona, España, disponible en http://manueldelgadoruiz.blogspot. $\mathrm{mx} / 2012 / 06 /$ jerarquizacion-por-rango-de. html [consultado en línea el 3 de mayo de 2015].

Franquesa, Jaume, 2007, "Vaciar y llenar, o la lógica espacial de la neoliberalización", en Revista Española de Investigaciones Sociológicas, núm. 118, pp. 123-150.

González, Sara, 2011, “Bilbao and Barcelona 'in motion'. How urban regeneration 'models' travel and mutate in the global flows of policy tourism”, en Urban Studies, núm. 48, pp. 1397-1418.

González, Sara y Paul Waley, 2012, "Retail Markets: The New Gentrification Frontier?”, en Antipode, vol. 45, pp. 965-983.

Guàrdia, Manuel, 2012, "Mercats i identitat alimentària”, en Barcelona Metropolis, núm. 86, pp. 12-16.

Güell, Oriol, "Una empresa compra la mayoría de los puestos del mercado de San Miguel", El País, 25 de octubre de 2005, disponible en http://elpais.com/diario/2005/10/25/ madrid/1130239457_850215.html [consultado en línea el 15 de agosto de 2015].

Harvey, David, 1989, "From managerialism to entrepeneurialism: the transformation in urban governance in late capitalism", en Geografiska Annaler, núm. 71, pp. 3-17. 
Hernández-Cordero, Adrián, 2014, “Gentrificación comercial y mercados públicos: El Mercado de Santa Caterina, Barcelona”, Working Paper Series Contested Cities, Madrid, España disponible en http://contested-cities.net/working-papers/2014/ gentrificacion-comercial-y-mercados-publicos-el-mercado-desanta-caterina-barcelona [consultado en línea el 15 de mayo de 2015].

Hiernaux, Daniel e Imelda Gonzalez, 2014, “Turismo y gentrificacion: pistas teóricas sobre una articulación”, en Norte Grande, núm. 58, pp. 55-70.

Instituto Municipal de Mercados de Barcelona, 2014, Pla estratègic mercats de Barcelona 2015/2025, IMMB, Barcelona.

Judd, Denis, 2003, "El turismo urbano y la geografía de la ciudad", en EURE, núm. 87, pp. 51-62.

López de Lucio, Ramón, 2002, "La vitalidad del espacio público urbano en riesgo", en Distribución y Consumo, núm. 26, pp. 25-41.

Marovelli, Brigida, 2014, "Meat Smells Like Corpses: Sensory Perceptions in a Sicilian Urban Marketplace", en Urbanities, núm. 2, pp. 21-38.

Massey, Doreen, 1995, “The conceptualization of place”, en Doreen Massey y Pat Jess (editores), A place in the world? Place, Culture and Globalization, Oxford, Oxford University Press, pp. 45-85. Massey, Joanne, 2005, "The Gentrification of Consumption: A View from Manchester”, en Sociological Research Online, vol. 10, issue 2, [en línea] disponible en http://www.socresonline.org. uk/10/2/massey1.html [fecha de consulta: 20 de enero de 2015].

Patch, Jason, 2008, "Ladies and Gentrification: New Stores, Residents, and Relationships in Neighborhood Change", en Research in Urban Sociology, núm. 9, pp. 103-126.

Robles, Juan, 2008, "Comercio urbano en espacios metropolitanos", en Distribución y Consumo, núm. 19, pp. 19-31.

Robles, Juan, 2010, "Pequeños comerciantes: mediadores urbanos”, en Revista Chilena de Antropología Visual, núm. 15, pp. 164-190. 
Romero, Luís y Laura Lara, 2015, “De barrio-problema a barrio de moda: gentrificación comercial en Russa-fa, El 'Soho' valenciano”, en Anales de Geografía de la Universidad Complutense, vol. 35, núm. 1, pp. 187-212.

Slater, Tom, 2011, "Gentrification of the City", en Gary Bridge y Sophie Watson (editores), The New Companion to the City, Blackwell, Oxford, pp. 571-585.

Smith, Neil, 2001, "Nuevo globalismo, nuevo urbanismo", en Documents d'Anàlisis Geogràfica, núm. 38, pp. 15-32.

Vázquez Montalbán, Manuel, 2001, La Boqueria: la catedral dels sentits, Institut de Mercats, Barcelona.

Watson, Sophie, 2009, “The Magic of the Marketplace: Sociality in a Neglected Public Space”, en Urban Studies, núm. 46, pp. 15771591.

Zukin, Sharon,1991, Landscapes of power: From Detroit to Disney World, University of California Press, Berkeley.

Zukin, Sharon, 2008, "Consuming authenticity", en Cultural Studies, núm. 5, pp. 724-748.

Zukin, Sharon, 2010, Naked city, Oxford University Press, New York. Zukin, Sharon, Valerie Trujillo, Peter Frase, Danielle Jackson, Tim Recuber y Abraham Walker, 2009, "New retail capital and neighborhood change: boutiques and gentrification in New York City”, en City \& Community, núm. 8, pp. 47-64. 